\title{
Purification and gene cloning of a novel antibacterial phospholipase A2 from the sponge Agelas clathroides in Kapoposang Island Indonesia terrestrial
}

\author{
Ahyar Ahmad, 2, ", Hasnah Natsir², Harningsih Karim ${ }^{3}$ \\ ${ }^{1}$ Laboratory of Research Centre and Developing of Sciences, Mathematic and Natural Science Faculty, Hasanuddin University, Jl. Perintis \\ Kemerdekaan KM 10, Makassar 90245, Indonesia \\ ${ }^{2}$ Laboratory of Biochemistry, Chemistry Department, Mathematic and Natural Science Faculty, Hasanuddin Univesity, Jl. Perintis \\ Kemerdekaan KM 10, Makassar 90245, Indonesia \\ ${ }^{3}$ Department of Pharmacy, School of Pharmacy YAMASI, Jl. Mapala 2 Blok D5 No.10 Makassar 90222, Indonesia
}

Email address:

ahyarahmad@gmail.com (A. Ahmad)

\section{To cite this article:}

Ahyar Ahmad, Hasnah Natsir, Harningsih Karim. Purification and Gene Cloning of a Novel Antibacterial Phospholipase A2 from the Sponge Agelas Clathroides In Kapoposang Island Indonesia Terrestrial. American Journal of Biomedical and Life Sciences.

Vol. 2, No. 5, 2014, pp. 119-126. doi: 10.11648/j.ajbls.20140205.13

\begin{abstract}
A new phospholipase A2 enzyme (PLA2) has been purified from the sponge of Agelas clathroides by using ammonium sulphate fractionation, column chromatography and reversed-phase HPLC. It behaves as a single-band on SDS-PAGE with molecular weight of $39 \mathrm{kDa}$. Based on amino acids partial sequence, we cloned and sequenced cDNA encoding PLA2. It consists of 474 nucleotides encoding 157 amino acid residues including a putative initiation Met. To obtain it in large amounts, the coding sequence of PLA2 was cloned into pGEX-2TK vector and expressed as a PLA2 fusion protein in Escherichia coli BL21 strain. The soluble fusion protein collected from the supernatant of the cell lysate with induction by 50 $\mu \mathrm{M}$ isopropyl- $\beta$-D-thiogalactopyranoside (IPTG) was purified in a single-step on glutathione agarose bead chromatography. The purified native PLA2 protein and recombinant PLA2 fusion protein were determinated for novel antibacterial activity. Recombinant PLA2 fusion protein exhibited a similar antibacterial activity to the native PLA2. The recombinant PLA2 had stronger antibacterial activity toward Salmonella typhy and Staphylococus aureus $\left(\mathrm{G}^{+}\right)$with the inhibition zone diameters of 2.0 times higher than that toward Echerichia coli and Vibrio cholerae $\left(\mathrm{G}^{-}\right)$. These works might provide a significant foundation for following research on the antibacterial action of PLA2 protein from marine sponges.
\end{abstract}

Keywords: Sponge, Agelas clathroides, Phospholipase A2, Recombinant Protein, Antibacterial Activity

\section{Introduction}

The evolution of antibiotic-resistant bacteria has stimulated the search for potent antibacterial agents from natural products. While natural products have traditionally been harvested from terrestrial sources, reports showed that more than 15.000 marine natural products have been isolated in the period from 1965 to $2005^{[1]}$. A major contributing factor to this development is the fact that modern biotechnology has made easier to gain access to the great biodiversity of life found in the oceans ${ }^{[2]}$. The marine environment offers a great biodiversity for the isolation of pharmacologically active compounds $^{[3]}$. Efficient high throughput screening methods have been developed to exploit the marine biodiversity including marine sponges (porifera) in drug discovery programs ${ }^{[3,4]}$. Since the early days of marine natural product discovery, Porifera (sponges) and Chordata have dominated as the major contributing phyla of novel bioactive compounds $^{[1]}$.

Phospholipase A2 (PLA2) catalyses the hydrolysis of the sn-2 acyl ester bond of phospholipids in a reaction resulting in the release of a free fatty acid and lysophospholipid. PLA2s are present as membrane-associated and soluble enzymes in almost all cell types and play important roles in the biosynthesis of eicosanoids, turnover of membrane phospholipids, cellular signalling and protection of membranes against peroxidation damage ${ }^{[5]}$. PLA2s are essential components of snake and other venoms where the various forms of the enzyme have haemolytic, myotoxic, 
neurotoxic, procoagulant and anticoagulant functions ${ }^{[6]}$. In humans, PLA2s are associated with numerous clinical inflammatory processes ${ }^{[7]}$. In addition, the human and mouse PLA2s are highly conserved in their amino acid sequence and tertiary structure. An important property of secretory PLA2s is their capability to kill bacteria in vitro ${ }^{[8]}$ and in vivo ${ }^{[9]}$.

The functional role of PLA2 in eicosanoid-mediated disorders makes this enzyme a potentially important therapeutic target ${ }^{[10]}$. The snake venom and mammalian PLA2s have been studied extensively and in detail; there are only few studies on the PLA2s of marine invertebrates ${ }^{[1]}$. In addition, distinct PLA2s have been characterised and cloned in a number of other animal species, including invertebrates ${ }^{[12]}$ and fish $^{[13]}$ as well as in plants ${ }^{[14]}$. To our knowledge, PLA2 has not been purified and cloned from sponge, especially from Indonesia terrestrial such as Kapoposang island. Indonesia, known as a maritime country with ocean area of $75 \%$ covering the country, has abundant source of marine biota, among others are a variety of sponges species. Some species have been reported to contain bioactive compounds that have been widely applied in pharmaceutical industries ${ }^{[15]}$. However, research on the exploration of certain groups of protein compounds derived from sponges as a whole material for medicines designated to human and animal has not been published so far.

In this study, we report for the first time, the purification and characterization of PLA2 from Agelas clathroides of marine sponges. Based on partial amino acid sequencing, cDNA encoding PLA2 was cloned and the amino acid sequence and structure was deduced, resulting high homology with cnidaria PLA2 (79\%). Finally, the recombinant gene encoding PLA2 was expressed in E. coli BL21 strain to produce recombinant GST-PLA2 fusion protein and it's antibacterial activity was compared with the native PLA2 protein. The results of this work indicated that recombinant PLA2 had stronger antibacterial activity toward $S$. typhy and $S$ aureus with the inhibition zones diameters of 2.0 times higher than that toward the other Gram negative bacterial test. Regarding the two strains of Gram negative $V$. cholerae and $E$. coli, the inhibition zones diameters were almost the same using lysozyme protein as positive control. Futhermore, this research is the first report on the purification and gene cloning of a novel antibacterial PLA2 of the marine sponge. These works might provide a significant foundation for following intensive and detailed research on the structural and action of molecular mechanism of PLA2 protein from marine sponges in drug discovery programs.

\section{Materials and Methods}

\subsection{Materials}

Materials used in this research were sponge Agelas clathroides (from Kapoposang island, South Sulawesi Province, Indonesia terrestrial), bacterial test of E. coli, $S$. aureus, S. typhi, and V.cholerae, aquades, MHA (Muller Hinton Agar) media, pGEX-2TK vector, CM-cellulose,
Sephadex G-75, E. coli BL-21 compotent cells, Trizol reagent kit, buffer A (Tris-HCl 0,1 M pH 8.3, $\mathrm{NaCl} 2 \mathrm{M}, \mathrm{CaCl}_{2} 0.01$ $\mathrm{M}, \quad \beta$ - mercaptoetanol $1 \%$, Triton X-100 $0.5 \%$ ), buffer $\mathrm{B}$ (Tris-HCl 0.1 M pH 8.3, $\mathrm{NaCl} 0.2 \mathrm{M}, \mathrm{CaCl}_{2} 0.01 \mathrm{M}$ ), buffer C (Tris-HCl 0.01 M pH 8.3, $\mathrm{NaCl} 0.2 \mathrm{M}, \mathrm{CaCl}_{2} 0.01 \mathrm{M}$ ), GST (Glutathion S-transferase), and lysozyme protein.

\subsection{Extraction and Isolation of Sponge PLA2 Protein}

Extraction and isolation of sponge PLA2 protein were conducted using previous methods as follows[16, 17], $500 \mathrm{~g}$ of fresh sample sponge Agelas clathroides, homogenized with waring blender in $500 \mathrm{~mL}$ of buffer A (Tris- $\mathrm{HCl} 0.1 \mathrm{M} \mathrm{pH} 8.3$, $\mathrm{NaCl} 2 \mathrm{M}, \mathrm{CaCl}_{2} 0.01 \mathrm{M}, \beta$-mercaptoetanol $1 \%$, Triton $\mathrm{X}$ $1000.5 \%$ ), filtered with buchner. The filtrate obtained was freezen and thawed between 2 or 3 times, and then centrifugized at $12,000 \mathrm{rpm}$ and $4^{\circ} \mathrm{C}$ for 30 minutes. The supernatant obtained was stored in a refrigerator until tested for antibacterial activity and further purification steps.

\subsection{Fractionation and Dialysis of Protein}

The supernatant (whole extracts) containing protein and having anti bacterial activities was then fractionated using ammonium sulphate at saturated levels of $0-20 \%, 20-40 \%$, $40-60 \%$, and $60-80 \%$, respectively.

The precipitates obtained after fractionation at optimum saturation level of ammonium sulphate was then resuspended in buffer B (Tris- $\mathrm{HCl} 0.1 \mathrm{M} \mathrm{pH} \mathrm{8.3,} \mathrm{NaCl} 0.2 \mathrm{M}, \mathrm{CaCl}_{2} 0.01$

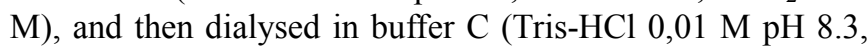
$\mathrm{NaCl} 0.2 \mathrm{M}, \mathrm{CaCl}_{2} 0.01 \mathrm{M}$ ) using selophan pocket (Sigma) until colorless. After dialysis, protein fraction was subjected to antibacterial testing similar to the previous testing on the preparate of whole extract protein.

\subsection{Purification of Native PLA2 Protein}

The protein fraction of ammonium sulphate with maximum antibacterial activity (100 mg) of Agelas clathroides was dissolved in $5 \mathrm{~mL}$ of $50 \mathrm{mM}$ Tris- $\mathrm{HCl}$ buffer $(\mathrm{pH} \mathrm{8.3)}$ and centrifuged (15,000 rpm, $5 \mathrm{~min})$. The supernatant were loaded onto a carboxymethyl cellulose (CM, Sigma-Aldrich) cation-exchange column ( 3 X $20 \mathrm{~cm})$ which had been equilibrated with $20 \mathrm{mM}$ Tris- $\mathrm{HCl}$ buffer ( $\mathrm{pH} \mathrm{8.3)}$. After the unbound proteins had been eluted, bound proteins wich antibacterial activity were eluted using a gradient from 20 to $1500 \mathrm{mM}$ Tris- $\mathrm{HCl}$ buffer $(\mathrm{pH} 8.3$ ) at a flow rate of 0.5 $\mathrm{mL} / \mathrm{min}$ and 60 fractions were collected. Protein fractions were lyophilized and then redissolved in $50 \mathrm{mM}$ Tris- $\mathrm{HCl}$ buffer ( $\mathrm{pH} \mathrm{8.3)} \mathrm{for} \mathrm{antibacterial} \mathrm{activity} \mathrm{assay.} \mathrm{Pooled} \mathrm{active}$ fractions were loaded onto a Sephadex G-75 gel filtration column (1 X $30 \mathrm{~cm}$, Amersham Pharmacia Biotech, Sweden). After the unbound proteins had been eluted, bound proteins wich antibacterial activity were eluted with the same buffer solution at a flow rate of $0.5 \mathrm{~mL} / \mathrm{min}$. The elution proteins was monitored at $280 \mathrm{~nm}$ by UV Spectrometer. The fractions were lyophilized and redissolved in $50 \mathrm{mM}$ Tris-HCl buffer $(\mathrm{pH} 8.3$ ) for antibacterial activity assay. Fractions showing antibacterial activity were subjected to reverse-phase high-performance 
liquid chromatography (RP-HPLC) on a C8 column (4.6 X $100 \mathrm{~mm}$, Amersham Pharmacia Biotech, Sweden) under a shallower gradient from 30 to $60 \%$ acetonitrile in $0.1 \%$ TFA over $60 \mathrm{~min}$, at a flow rate of $0.5 \mathrm{~mL} / \mathrm{min}$. The elution proteins was monitored at $214 \mathrm{~nm}$ by UV Spectrometer. After each step, the protein profiles of the active fractions were analyzed by sodium dodecyl sulfate-polyacrylamide gel electrophoresis (SDS-PAGE) with 10\% separating gel. Proteins were detected by Coomassie Brilliant Blue R staining.

\subsection{Protein Concentration Quantitative}

The calculation of protein concentration at different purification steps was determined based on Lowry method ${ }^{[18]}$ using Bovine Serum Albumine (BSA) as a standard.

\subsection{Determination of Partial Amino Acid Sequences of $P L A 2$}

The purified native PLA2 $(20-30 \mu \mathrm{g})$ was subjected to sodium dodecyl sulfate-polyacrylamide gel electrophoresis (SDS-PAGE) with 10\% separating gel. Proteins were detected by Coomassie Brilliant Blue $\mathrm{R}$ staining. A single band corresponding to the PLA2 protein was extracted from gel, and the high purity protein was treated with lysyl-endopeptidase enzyme in $100 \mu \mathrm{L}$ of $50 \mathrm{mM}$ Tris- $\mathrm{HCl}$ buffer ( $\mathrm{pH} 8.3$ ), at PLA2 protein ratio of 1:20 by weight for 10 $\mathrm{h}$ at $30^{\circ} \mathrm{C}$. Acetonitrile was added to the reaction mixture at a final concentration of $5 \%(\mathrm{v} / \mathrm{v})$ followed by sonication for 5 $\min$. The mixture was centrifuged at $15,000 \mathrm{rpm}$ for $1 \mathrm{~min}$ at $4^{\circ} \mathrm{C}$, and the supernatant (peptides) was applied to a protein sequencer (Applied Biosystems Division, Model 473A, Perkin-Elmer).

\subsection{Preparation of the Total RNA from Sponge Agelas Clathroides}

The sponge Agelas clathroides was cut into small peices and homogenized by adding Trizol reagent (Gibco BRL) immediately after removal to new eppendorf tube. Total RNA was extracted according to the manufacturer's protocol (Gibco BRL).

\section{8. cDNA Synthesis and Molecular Cloning of the Gene Encoding PLA2 Protein}

Based on the known partial amino acid sequence and homogenous analysis by Protein Sequencing and BLASTN program $^{[19]}$, two primers $\mathrm{P} 1$ and $\mathrm{P} 2$ were designed (P1: 5'-CTTGCTTTGGCTGATCAAGAAAATAAG-3', P2: 5'GTTAAAATGATTCCTCATGAAACACTT-3'). RT-PCR kit (Takara, Japan) was used to amplify the $3^{\prime}$ end of cDNA, in which primers P1 and P2, Oligo dT-Adaptor primer M13 and primer M4 were used according to the manufacturer's protocol (Takara, Japan). After that, primer P3 (5'-TCCCGGCCTGCAGAGACTTAGC-3') was designed near the $3^{\prime}$ end of cDNA. RT-PCR was performed to obtain the encoded region of cDNA by using primer P1 and P3. Next, cDNA product encoding full length of PLA2 protein was cloning into pGEX-2TK vector to yield pGEX-2TK PLA2 cDNA plasmid.

\section{9. cDNA Sequencing and Analysis}

The nucleotide sequence was analyzed by the dideoxy chain-termination method using DNA sequencer machinery (Applied Biosystems ABI Prism 310). The cDNA sequence and deduced amino acid sequence were compared with sequences in the GenBank database through BLASTN, BLASTP, and Bioedit 7.9.1 software ${ }^{[19]}$.

\subsection{Expression of Recombinant GST-PLA2 Fusion Protein in E.coli}

The GST Gene Fusion System (Pharmacia Biotech Inc.) was used to express PLA2 following the procedure of Ahmad, et al., 1999 $9^{[20] .}$ An overnight culture of E. coli BL21 containing pGEX-2T PLA2 cDNA was diluted 1:10 in $400 \mathrm{~mL}$ of LB medium supplemented with $200 \mu \mathrm{g} / \mathrm{mL}$ ampicillin, and next grown at $37^{\circ} \mathrm{C}$ to an optical density (OD) 600 of 1.0 and induced with $50 \mu \mathrm{M}$ IPTG for $3 \mathrm{~h}$ at $37^{\circ} \mathrm{C}$. The culture $(400$ $\mathrm{mL}$ ) was centrifuged and the pellet suspended in $10 \mathrm{ml}$ of lysis buffer (Tris- $\mathrm{HCl} 0.1 \mathrm{M} \mathrm{pH} \mathrm{8.3,} \mathrm{NaCl} 2 \mathrm{M}, \mathrm{CaCl}_{2} 0.01 \mathrm{M}$, $\beta$-mercaptoetanol $1 \%$, Triton X- $1000.5 \%$ ), containing $0.1 \%(\mathrm{v} / \mathrm{v})$ phenylbenzosulfonyl fluoride and $1 \mathrm{mg} / \mathrm{mL}$ lysozyme. Following a 15-min incubation on ice, dithiothreitol and Sarkosyl were added to $5 \mathrm{mM}$ and $1.5 \%$ final volumes, respectively. The sample was sonicated for 2 $\mathrm{min}$ on ice in a water bath sonicator, centrifuged, and Triton-X 100 ( $2 \%$ final volume) was added to the supernatant. Next, glutathione agarose beads were added to the supernatant and incubated for $20 \mathrm{~min}$ at $4^{\circ} \mathrm{C}$ with gentle rotation. The beads were collected by centrifugation at 3,500 rpm for 2 min and washed five times with cold PBS buffer. The fusion protein (GST-PLA2) were eluted with $4 \mathrm{~mL}$ of $20 \mathrm{mM}$ glutathione in $50 \mathrm{mM}$ Tris- $\mathrm{HCl} \mathrm{pH} \mathrm{8.3,} \mathrm{and} \mathrm{the} \mathrm{resultant} \mathrm{eluate} \mathrm{was}$ concentrated with a Millipore membrane, followed by the addition of glycerol to a final concentration of $20 \%$. The samples obtained were resolved by $10 \%$ SDS-PAGE, as described $^{[20]}$. The recombinant GST-PLA2 fusion protein concentrations were determined by Lowry method ${ }^{[18]}$ using Bovine Serum Albumine (BSA) as a standard. The antibacterial activity of the recombinant GST-PLA2 fusion protein together with the native PLA2 protein was determined as later described.

\subsection{Antibacterial Activity Assays}

Antibacterial activity assays against E. coli, S. aureus, S. typhi, and $V$. cholerae was conducted using diffusion method $[16,17]$. All about $20 \mu \mathrm{L}$ of samples (whole extract and protein fractions obtained at each purification step, approximately 4 $\mu \mathrm{g}$ ), were applied on sterile paper disc (diameter $6 \mathrm{~mm}$ ) and put on the agar surface of the bacterial test culture. After one day $(24 \mathrm{~h})$ incubation at $37^{\circ} \mathrm{C}$, the inhibition zone diameter was determined in milimeter. The same procedure was applied to $20 \mu \mathrm{L}$ GST alone (approximately $4 \mu \mathrm{g}$ ) and $20 \mu \mathrm{L}$ lysozyme (approximately $4 \mu \mathrm{g}$ ) as negative and positive controls, respectively. The assay was conducted in duplicate and repeated three times to produce representative experimental data. 


\section{Results}

\subsection{Purification of Native PLA2 Protein}

Protein fraction from ammonium sulphate fractionation was applied on a CM-cellulose cation-exchange column (3 X 20 $\mathrm{cm})$, and the proteins bound to the $\mathrm{CM}$ were eluted using a gradient from 20 to $1500 \mathrm{mM}$ Tris- $\mathrm{HCl} \mathrm{pH} 8.3$ at a flow rate of $0.5 \mathrm{ml} / \mathrm{min}$ and 60 fractions were collected up to $600 \mathrm{~min}$. The fractions eluting between 0.6 and $1.2 \mathrm{M}$ Tris- $\mathrm{HCl}$ demonstrated antibacterial activity (Figure 1A). The protein fraction from CM-Cellulose cation-exchange column that

\section{A}
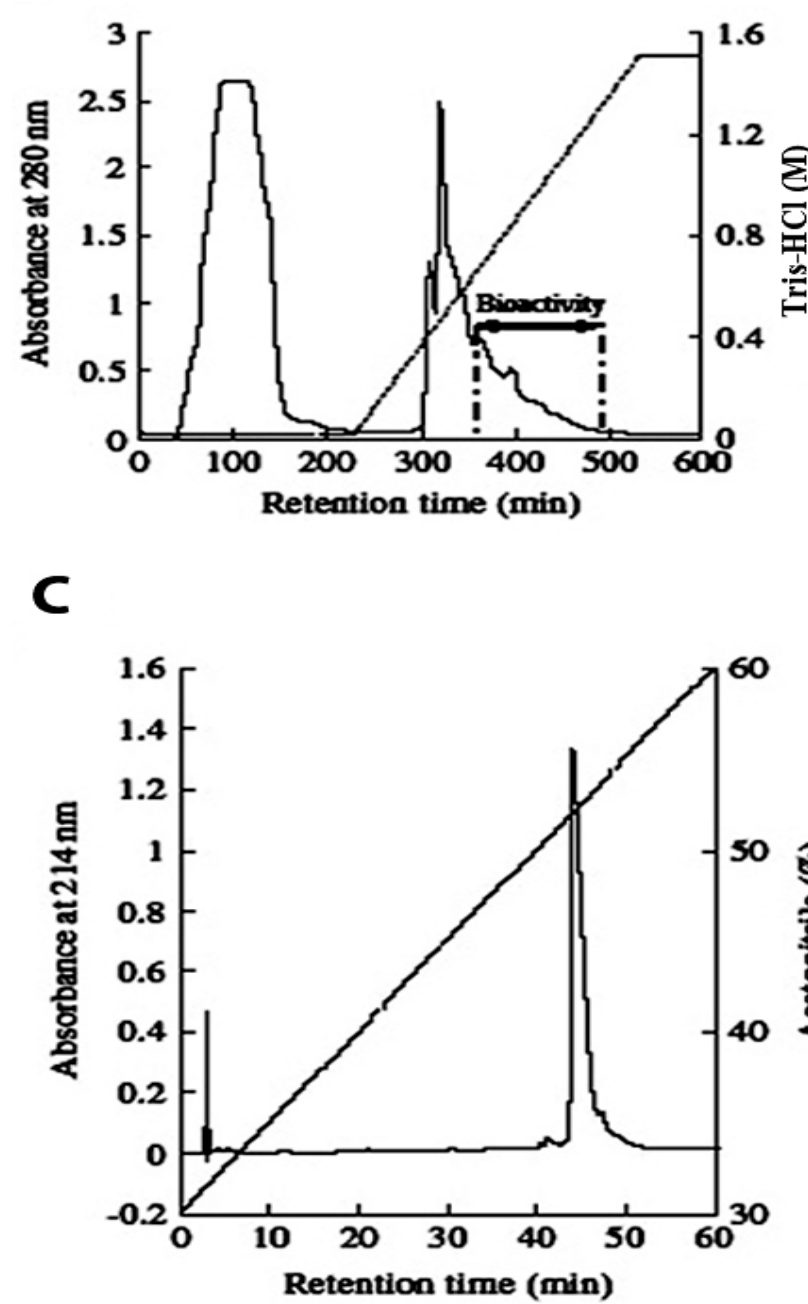

demonstrated antibacterial activity were applied to gel filtration chromatography on Sephadex-G75. Nine peaks were collected out of which only peak 9 showed antibacterial activity (Figure $1 \mathrm{~B}$ ). For protein sequencing, peak 9 was further purified by reversed-phase HPLC on a C8 column using a shallower acetonitrile gradient, resulting in single protein purity (Figure $1 \mathrm{C}$ ). Based on SDS-PAGE (10\%), the molecular weight of the purified PLA2 protein was estimated to be around $39 \mathrm{kDa}$ (Figure 1 D). The result was similar to the one calculation based on Bioedit 7.9.1 software which showed that the molecular weight was $38.979 \mathrm{kDa}$ (result not shown).

\section{B}

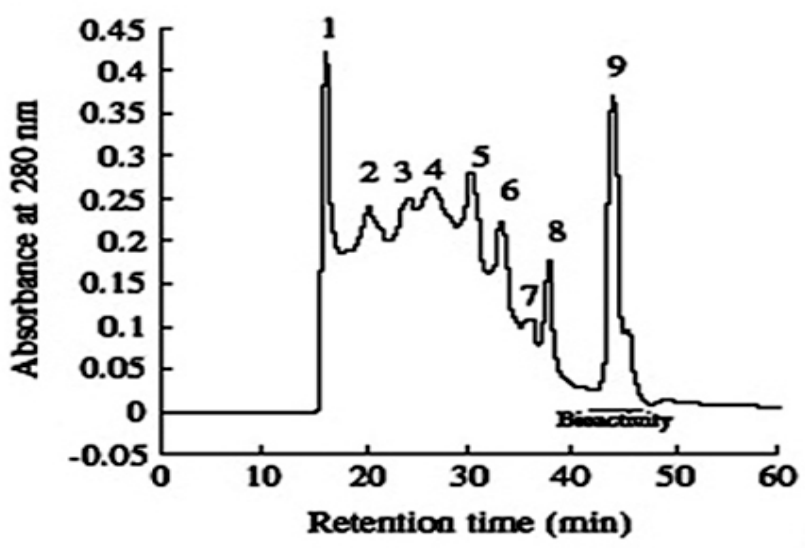

D

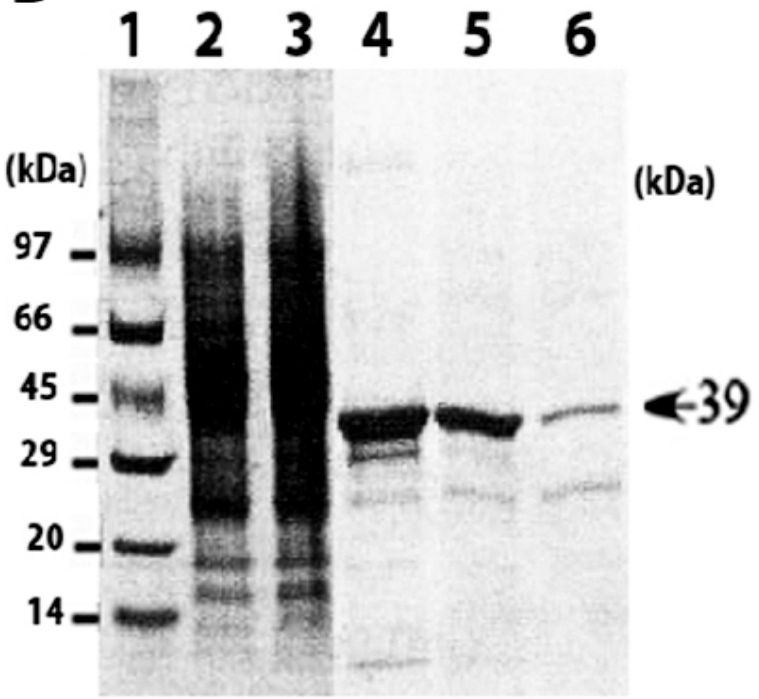

Figure 1. Isolation and purification steps of a novel antibacterial PLA2 protein from the sponge Agelas clathroides.

As shown in Figure 1, (A) Cation-exchange chromatography of protein fraction on CM-Cellulose. (B) Gel filtration chromatography of pooled active fractions from the cation-exchange column on a Sephadex G-75 column (C) Pure protein of peak 9 from gel filtration chromatography in (B) was purified by reversed-phase HPLC on a C8 column. (D) SDS-PAGE (10\%) analysis of the active fractions obtained at each purification step. Lane 1, Protein marker in $\mathrm{kDa}$; lane 2, whole extract materials; lane 3, protein fraction from ammonium sulphate fractionation; lane 4, pooled active fractions from CM cation-exchange chromatography; lane 5, pooled active fractions (peak 9) from gel filtration chromatography; lane 6 , single peak from the reversed-phase HPLC.

\subsection{Amino Acid Sequencing and Gene Cloning Encoding PLA2 Protein}

At first, 11 residues amino acids (LALADQENKSL) and 12 residues amino acids (VKCFMRNHFNNK) were determined by direct $\mathrm{N}$-terminal amino acid sequencing of 
PLA2 protein using Protein Sequencer. In order to obtain the complete amino acid sequence of the mature PLA2 protein, RT-PCR and cDNA sequencing were further performed. The primers for RT-PCR were designed based on the partial amino acid sequence above, and a full length cDNA fragment of about $541 \mathrm{bp}$, including untranslation regions was obtained. The fragment DNA was cloned into the pGEX-2TK vector to yield pGEX-2TK PLA2 cDNA plasmid (Figure 2) and than sequenced. The complete amino acid sequence was then deduced from the cDNA sequence. It shows the mature PLA2 protein that contains an open reading frame (ORF) of 610 nucleotides, including the untranslation regions poly $\mathrm{A}^{+}$ ending and encoded 157 amino acid residues including initiation Met (Figure 3). Based on Bioedit 7.9.1 software, the amino acids sequence revealed high homology with the PLA2 protein cnidaria $(78 \%)$, but low homology with the PLA2 protein Echinodermata (12\%), and very low homology with the PLA2 protein chordata $(6 \%)$ (Figure 4). This results indicated that the fragment DNA isolated from sponge Agelas clathroides from Kapoposang island, South Sulawesi Province, Indonesia was a gene encoding PLA2 protein, and also this gene could be amplified using the generated primer pairs from the partial amino acid sequence of native PLA2 protein. Future intensive research is needed to trace the existence of this gene and it's product, especially for determination of enzymatic activity to strengthen the structural and functional analysis of PLA2 protein.
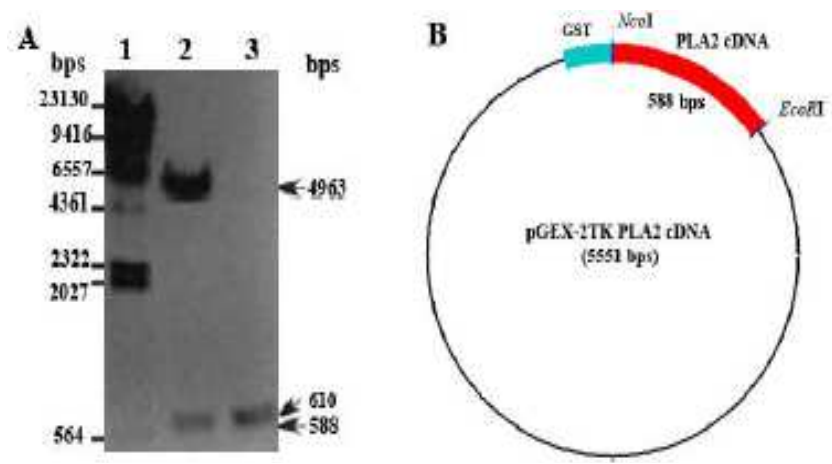

Figure 2. Schematic representation of the PLA2 gene synthesis by the RT-PCR method and the construction of $p G E X-2 T K$ fusion vector.

As shown in Figure 2, A) Agarose gel electrophoresis of DNA fragment of RT-PCR product. Lane 1, DNA lambda/HindIII marker; lane 2, two fragments DNA containing pGEX-2TK vector (4963 bps) and insert of PLA2 DNA minus 5 ' untranslation region (588 bps) digested by NcoI/EcoRI restriction enzymes of recombinant plasmid in B; and lane 3, RT-PCR product of PLA2 DNA (610 bps). B) Restriction map of recombinant pGEX-2TK PLA2 cDNA plasmid.

The nucleotide sequence was analyzed by the dideoxy chain-termination method. As shown in Figure 3, the result of N-terminal amino acid sequencing obtained from Protein Sequencing is indicated in box and the two primers P1 and P2 obtained based on partial amino acids sequencing are underlined. ccaacgatatccgtgcgcacct

$-22$

$\begin{array}{lll}1 & \text { atg cag ctt tat acc gtt ttt ttc acc gcg tct gtt gtg gta att } & 45 \\ 1 & \text { Met Gln Leu Tyr Thr Val Phe Phe Thr Ala Ser val Val Val Ile } & 15\end{array}$ 46 ctt gct ttg gct gat caa gaa aat aag tca tta gac ttc att tcg 90

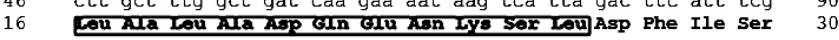

91 gaa ggt gga att gcc ggg cga ggg gat ttt cag gac agt gcc cta 135 $\begin{array}{lll}91 & \text { gaa ggt gga att gcC ggg cga ggg gat ttt cag gac agt gcc cta } & 135 \\ 31 & \text { Glu Gly Gly Ile Ala Gly Arg Gly Asp Phe Gln Asp Ser Ala Leu } & 45\end{array}$

136 atc aaa aaa tat acg gga cgc aat cca ttg gat ccg tgg gat tat 180 46 Ile Lys Lys Tyr Thr Gly Arg Asn Pro Leu Asp Pro Trp Asp Tyr 60

181 ggc tgc tgg tgt gga cta ggt ggc gat gga acg tac gtt gat gtc 225 61 Gly Cys TrP Cys Gly Leu Gly GIY Asp Gly Thr Tyr val Asp val 75

226 gta gcg tgg tgc gac tac cat cac gac atg ccc ttc aat agt ggt 270 76 Val Ala Trp Cys Asp Tyr His His Asp Met Pro Phe Asn Ser Gly 90

271 tac caa ggg gaa cgc cca act tgc agc tct aac gca cct gtc cat 91 Tyr Gln Gly Glu Arg Pro Thr cys Ser Ser Asn Ala pro Val His

316 aag aac tac tat ttc agc ggt ctc aaa tgt tcg aca ggt tgg ccc 106 Lys Asn Tyr Tyr Phe Ser Gly Leu Lys Cys Ser Thr Gly Trp Pro

361 aca tgc aag tgt gga cga tgc att tgt gct tgt gcg att gct cag Thr Cys Lys Cys Gly Arg Cys Ile Cys Ala Cys Ala Ile Ala Gln

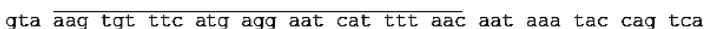
Val Lys Cys Phe Met Arg Asn His Phe Asn Asn Lys Tyr Gln Ser

tac gac aaa aat atc tgt tgc tag tgaaaaatggctgtataactgaattaa Tyr Asp Lys Asn Ile Cys Cys End

atatagaaatatcatgtataacataaatacagaacttacagatctgcgagtgagattac ctgtgttacatctgaaaaaaaaaaaaa

Figure 3. The cDNA and deduced amino acid sequence of PLA2 protein. Fragment achieved by RT-PCR amplification of total sponge Agelas clathroides cDNAs was inserted into $p G E X-2 T K$ vector.

The complete amino acid sequences of four proteins of marine invertebrate are shown in Figure 4. The positions of the amino acid sequence are indicated at the ends. Amino acid residues that are identical in two are marked with : and three are marked with . and analogous amino acids in all these proteins are indicated by bold letter.

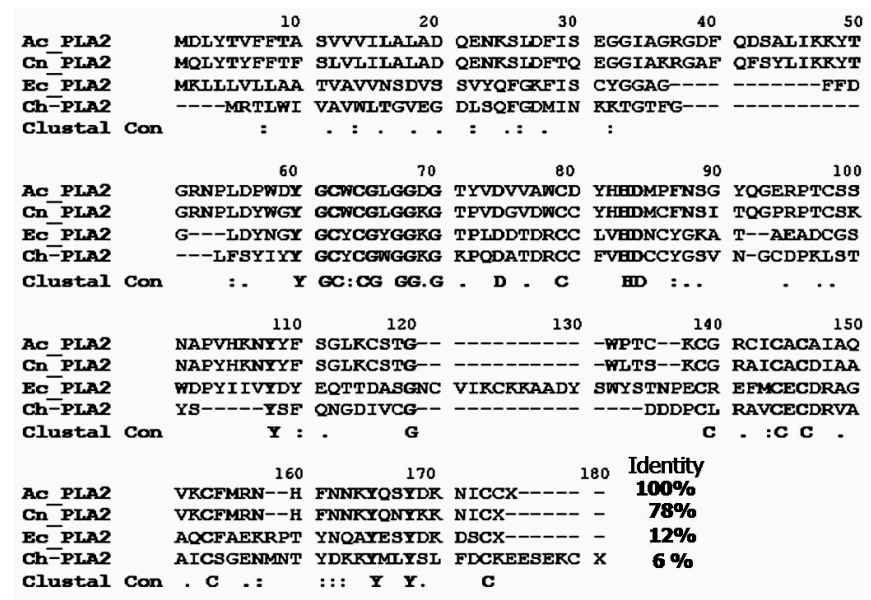

Figure 4. Comparison of the aligned amino acid sequences of PLA2 of sponge Agelas clathroides (ac_PLA2) with chordata (ch_PLA2), echinodermata(ec_PLA2), and cnidaria (cn_PLA2).

\subsection{Expression and Purification of the Recombinant PLA2 Protein}

The coding sequence of cDNA PLA2 was expressed as part of the pGEX-2T fusion protein, GST-PLA2. The single-step purification procedure as described in Ahmad, et al., $1999^{[20]}$, was used to improve solubility of the GST-PLA2 fusion protein. Based on SDS-PAGE (10\%) in Figure 5, the molecular mass of the GST-PLA2 fusion protein product was 
$\approx 65 \mathrm{kDa}$ (fusion of the molecular mass of the PLA2 alone was $\approx 39 \mathrm{kDa}$ plus the GST was $\approx 26 \mathrm{kDa}$ ) was dramatically accumulated in E.coli BL 21 cell containing the pGEX-2TK PLA2 plasmid with induction by $50 \mu \mathrm{M}$ IPTG and could be purified to more than $95 \%$ homogeneity, using glutathione agarose beads (see lane 4 in Figure 5).

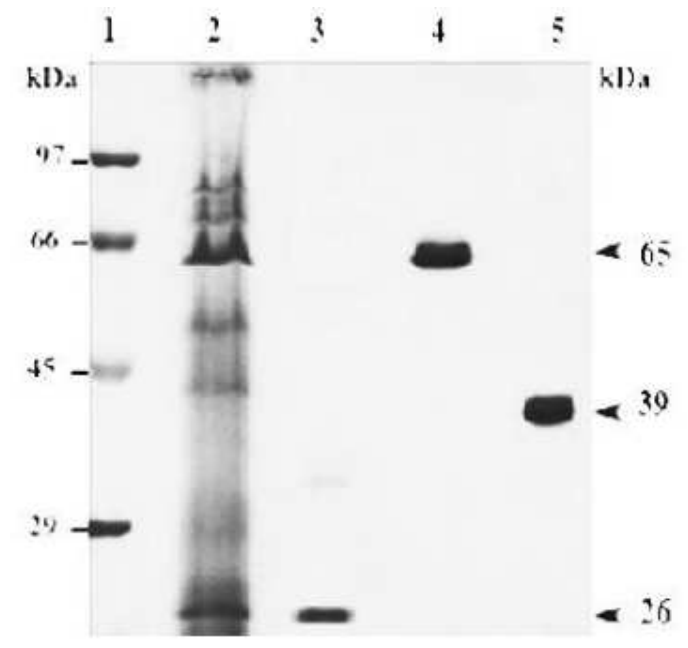

Figure 5. Electrophoresis SDS-PAGE (10\%) analysis of the recombinant GST-PLA2 fusion protein and native PLA2 protein.

As shown in Figure 5, Lane 1, Protein marker; Lane 2, Whole extract protein in $E$. coli cell containing pGEX-2TK PLA2 cDNA; Lane 3, GST protein; Lane 4, GST-PLA2 fusion protein; and Lane 5, native PLA2 protein.

\subsection{Antibacterial Activity of the Recombinant GST-PLA2 Fusion Protein}

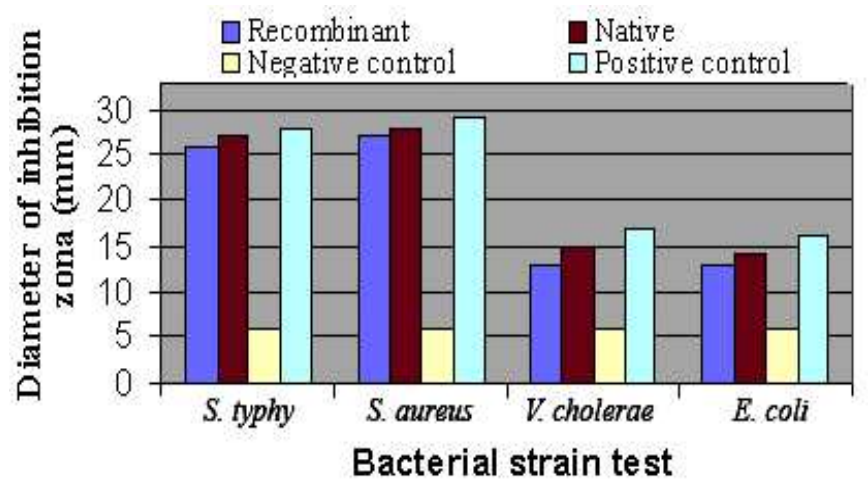

Figure 6. The diameters of inhibition zone resulting from the expression of the native PLA2 and recombinant of GST-PLA2 fusion protein (approximately 4 $\mu g$ ), negative control (GST, approximately $4 \mu g$ ), and positive control (lysozyme, approximately $4 \mu \mathrm{g}$ ) against different bacterial strain test.

The antibacterial activity of the recombinant GST-PLA2 fusion protein against different bacterial tests was performed by agar diffusion assay. The recombinant PLA2 displayed antibacterial activity not only against $S$. typhy and $S$. aureus (Gram positive) but also against strains of E.coli and $V$. cholerae (Gram negative). The inhibitory effect of the recombinant PLA2 was observed towards S. typhy, S. aureus, $V$. cholerae and E.coli strains with the inhibition zone diameters of $24 \mathrm{~mm}, 23 \mathrm{~mm}, 13 \mathrm{~mm}$, and $13 \mathrm{~mm}$ respectively, similar to native PLA2. The negative control of GST protein in the same concentration had no corresponding antibacterial activity on any of the bacterial strain test. The recombinant PLA2 had stronger antibacterial activity toward $S$. typhy and $S$ aureus with the inhibition zones diameters of 2.0 times higher than that toward other Gram negative bacteria. Regarding the two strains of Gram negative $V$. cholerae and E. coli the inhibition zones diameters were almost the same using lysozyme (approximately $4 \mu \mathrm{g}$ ) as positive control (Figure 6).

\section{Discussion}

In the current study, we purified and cloned a novel antibacterial PLA2 protein from a sponge Agelas clathroides, belonging to the phylum porifera. Recently Nevalainen et al. $2004^{[17]}$, showed the wide distribution of PLA2 in porifera and it's possible functional role in the defense system of marine sponges. In general PLA2, a hydrolytic enzyme, catalyzes the cleavage of the sn-2 acyl ester bond of phospholipases, resulting in the release of a free fatty acid and lysophospholipid. Sessile organisms like sponges are dependent on chemical defense and protective mechanisms other than active defense including migration, hiding, and physical attack. Depending on habitat changes, the appearance of a predator or pathogen, and other stress factors they are exposed to, sessile animals follow different strategies. The first-line defense against sudden stress factors is the transformation of inactive precursor compounds stored in the tissue of the affected organism, thereby yielding transformation products that exhibit a pronounced defensive activity. PLA2 is a ubiquitous defense enzyme found in snake and bee venoms and distributed throughout the plant and animal kingdom ${ }^{[21]}$. Recent studies suggested that varying levels of PLA2 were found in marine invertebrates including Porifera $^{[17]}$, Cnidaria ${ }^{[22]}$, and Echinodermata ${ }^{[12]}$. It has been reported that the cell proliferation of marine sponges is mediated by PLA2 ${ }^{[23]}$. But purification and cloning of PLA2 from sponge, especially from Indonesia terrestrial such as Kapoposang island has not been reported so far. On the other hand, the bactericidal activity of a full set of recombinant human and murine sPLA2s was tested against $L$. monocytogenes, $S$. aureus and E. coli ${ }^{[8]}$. All our preliminary results indicated that recombinant PLA2 protein was a potential antibacterial protein with possible effect on the host immune response.

Many antibacterial screening studies have shown that Gram-positive bacteria are more sensitive than Gram-negative bacteria to extracts of sponges and ascidians ${ }^{[24,25]}$. In fact, out of 777 species of sponges collected from the Caribbean Sea, $35 \%$ had activity against Gram-positive bacteria, 15\% had activity against Gram-negative bacteria. This is in agreement with our results, where sponge Agelas clathroides PLA2 protein extracted by polar solvent (Tris- $\mathrm{HCl}$ buffer) tested showed stronger activity (active at a concentration of 0.2 $\mu \mathrm{g} / \mu \mathrm{L}$, approximately $4 \mu \mathrm{g}$ ) against Gram-positive than Gram-negative bacteria strains. Further investigation should 
be conducted to confirm whether recombinant PLA2 protein is really involved in invertebrates immune response mechanisms, emphasizing the protein's dynamic change before and after microbe challenge, with antibodies to the recombinant PLA2 protein.

\section{Conclusions}

In this research, a novel antibacterial PLA2 with molecular weight of $39 \mathrm{kDa}$ from sponge Agelas clathroides was characterized, and its cDNA with 474 nucleotides including initiation and stop codon was cloned and expressed in E. coli as recombinant GST-PLA2 fusion protein. Our results indicate that PLA2 from sponge Agelas clathroides acts primarily on Gram-positive bacteria.

\section{Acknowledgements}

The author thanks Andis Sugrani for invaluable help and technical assistance, and the head of Biochemistry Laboratory and Microbiology and Immunology Laboratory of Hasanuddin University Indonesia for sample preparation and antibacterial testings. The author also thanks Paulina Taba for editorial reading of the manuscript. This work was supported in part by the Department of Education and Culture of Indonesia through Directorate General of Higher Education (DGHE) on Scheme Program for Academic Mobility and Exchange (SAME) Program Fiscal year 2014.

\section{References}

[1] Blunt, J.W., Copp, B.R., Hu, W.-P., Munro, M.H.G., and Northcote, P.T. Principle of Marine natural products, Nat. Prod. Rep. 24: 31-86, (2007).

[2] Battershill, Jaspars, M., and Long P. Marine biodiscovery: new drugs from the ocean depths, Biologist 52: 107-114, (2005).

[3] Quinn, R.J., Leone, P.D., Guymer, G., Hooper, J.N.A., Australian biodiversity via its plants and marine organisms. A high-throughput screening approach to drug discovery. Pure Appl. Chem. 74, 519-526, (2002).

[4] Hooper, J.N.A., van Soest, R.W.M. (Eds.), System Porifera: A Guide to the Classification of Sponges, Vol. 1 and 2. Kluwer Academicy Plenum Publishers, New York, (2002).

[5] Balsinde, J., Winstead, M.V., Dennis, E.A., Phospholipase A2 regulation of arachidonic acid metabolism. FEBS Lett. 531, $2-6,(2002)$.

[6] Davidson F.F. and Dennis, E.A., Amino acid sequence and circular dichroism of Indian cobra (Naja naja naja) venom acidic phospholipase A2. Biochim. Biophys. Acta 1037, 7-15, (1990).

[7] Nevalainen, T.J., Haapamaki, M.M., Gronroos, J.M., Roles of secretory phospholipases A2 in inflammatory diseases and trauma. Biochim. Biophys. Acta 1488, 83-90, (2000).

[8] Koduri, R.S., Grönroos, J.O., Laine, V.J.O., Le Calvez, C., Lambeau, G., Nevalainen, T.J., and Gelb, M.H., Bactericidal properties of human and murine groups I, II, V, X, and XII secreted phospholipases A2, J. Biol. Chem. 277: 5849-5857, (2002).

[9] Laine V.J.O., Grass D.S., Nevalainen T.J., Protection by group II phospholipase 2 against Staphylococcus aureus. J Immunol 162:7402-7408, (1999).

[10] Scott, K.F., Graham, G.G., Bryant, K.J., Secreted phospholipase A2 enzymes as therapeutic targets. Expert Opin. Ther. Targets 7, 427-440, (2003).

[11] Nevalainen, T.J., Llewellyn, L.E., Benzie, J.A.H., Phospholipase A2 in marine invertebrates. Rapp. Comm. Int. Mer Medit. 36, 202, (2001).

[12] Kishimura, H. Ojima, T. Hayashi, K. and Nishita, K., cDNA cloning and sequencing of phospholipase A2 from the pyloric ceca of the starfish Asterina pectinifera. Comp. Biochem. Physiol. 126, 579-586, (2000).

[13] Iijima, N. Uchiyama, S. Fujikawa, Y. and Esaka, M. Purification, characterization, and molecular cloning of group I phospholipase A2 from the gills of the red sea bream, Pagrus major. Lipids 35, 1359-1369, (2000).

[14] Ståhl, U. Lee, M. Sjödahl, S. et al., Plant low-molecular-weight phospholipase A2s (PLA2s) are structurally related to the animal secretory PLA2s and are present as a family of isoforms in rice (Oryza sativa). Plant Mol. Biol. 41, 481-490, (1999).

[15] Ilham, A. and Ahmad, A., Isolation and Characterization of Bioactive Protein from Several Species of Sponges As Antimicrobial Agent, In The Proceeding6th International Seminar of Indonesian Sociey for Microbiology, Pontianak Indonesia, (2013).

[16] Schro"der, H.C., Ushijima, H., Krasko, A., Gamulin, V., Thakur, N.L., Diehl-Seifert, B., Muller, I.M., and Muller, W.E.G., Emergence and Disappearance of an immune molecule, an antimicrobial lectin, in basal metazoan. A TACHYLECTIN-RELATED PROTEIN IN THE SPONGE SUBERITES DOMUNCULA. J. Biol. Chem., 278: 32810-32817, (2003).

[17] Nevalainen T. J., Quinn R. J., and Hooper, J. N.A., Phospholipase A2 in porifera. Comparative Biochemistry and Physiology Part B 137: 413-420, (2004).

[18] Lowry, O.H., Rosenbrough, N.J., Farr A.L., and Randall, R.L., Protein measurements with the Folin phenol reagent. J. Biol. Chem. 19: 265-275, (1951).

[19] Altschul, S.F., Madden, T.L., and Schäffer, A.A., Gapped BLAST and PSI-BLAST: a new generation of protein database search programs. Nucleic Acids Res. 25: 3389-3402, (1997).

[20] Ahmad, A., Takami, Y. and Nakayama, T., WD repeats of the p48 subunit of chicken chromatin assembly factor-1 required for in vitro interaction with chicken histone deacetylase-2. J. Biol. Chem., 274, 16646-16653, (1999).

[21] Stahl, U., Lee. M., and Sjodahl, S., Plant low-molecular weight phospholipase A2s (PLA2s) are structurally related to the animal secretory PLA2s and are present as a family of isoformas in rice (Oryza sativa). Plant Mol Biol 41: 481-490, (1999).

[22] Nevalainen, T.J., Peuravuori, H.J., Quinn, R.J., Llewellyn, L.E., Benzie, J.A.H., Fenner, P.J., Winkel, K.D., Phospholipase A2 in Cnidaria. Comp Biochem Physiol Part B 139: 731-735, (2004). 
[23] Gramzow, M, Schro"der, H.C., Fritsche, U., Kurelec, B., Robitzki, A., Zimmermann, H, Friese, K, Kreuter, M.H., and Mu"ller, W.E., Role of phospholipase A2 in the stimulation of sponge cell proliferation by homologous lectin. Cell 5: 939-948, (1989).
[24] Amade, P., Charroin, C., Baby, C., and Vacelet, J., Antimicrobial activities of marine sponges from the Mediterranean Sea, Marine Biology, 94 (2), 271-275, (1987).

[25] Rinehart, K.L. Biologically active marine natural products. Pure and Appl. Chem. 61, 525-528, (1989). 